\title{
$\mathrm{R} C \& \mathrm{C}$
}

\author{
TRANSPARÊNCIA E PARTICIPAÇÃO SOCIAL DA GESTÃO \\ PÚBLICA: ANÁLISE CRÍTICA DAS PROPOSTAS \\ APRESENTADAS NA $1^{\text {a }}$ CONFERÊNCIA NACIONAL SOBRE \\ TRANSPARÊNCIA PÚBLICA
}

\section{TRANSPARENCY AND SOCIAL PARTICIPATION IN PUBLIC MANAGEMENT: A CRITICAL ANALYSIS OF PROPOSALS SUBMITTED IN $1^{\text {ST NATIONAL }}$ CONFERENCE ON PUBLIC TRANSPARENCY}

Recebido em 05.08.2013 | Aceite final em 18.02.2014 |

Nota: este artigo foi aceito pelo Editor Jorge Eduardo Scarpin e passou por uma avaliação double blind review A reprodução dos artigos, total ou parcial, pode ser feita desde que citada a fonte.

VANUZA DA SILVA FIGUEIREDO Mestre em Ciências Contábeis | Universidade Estadual do Rio de Janeiro | Contadora do Instituto Macaé de Metrologia e Tecnologia | Rua Alcyr Amorin 19 | Bacaxá | Saquarema-RJ | Brasil | CEP 28993-000 | Telefone (+5522) 9276-4554 | E-mail: vanuzafigueiredo@hotmail.com |

WALDIR JORGE LADEIRA DOS SANTOS Doutor em políticas públicas | Universidade Estadual do Rio de Janeiro | Professor da Universidade do Estado do Rio de Janeiro | Rua São Francisco Xavier 524 | 9 andar | Bloco E | Maracanã |Rio de Janeiro-RJ |Brasil | CEP 20550-013 | Telefone (+5521) 2334-0294 | E-mail: wcladeira@uol.com.br |

\section{RESUMO}

Este estudo visa a contribuir para a reflexão sobre transparência e participação social da gestão pública brasileira, realizando uma análise crítica sobre as propostas elaboradas pelos participantes da 1a Conferência Nacional sobre Transparência e Controle Social (Consocial) no seu eixo 1. Por meio da análise, buscou-se identificar se as propostas elaboradas pela sociedade durante a 1a Consocial contribuíram para o exercício do controle social com base na transparência e no acesso a informação. A metodologia utilizada foi a pesquisa exploratória e a pesquisa participante. Por meio da análise das propostas priorizadas na última etapa da 1 a Consocial, observou-se a necessidade de uma maior divulgação das informações referente à administração pública, à exteriorização das competências dos instrumentos de participação social e à capacitação do cidadão para o exercício da participação social. Algumas falhas foram detectadas na formulação das propostas, como o desconhecimento dos participantes a 
respeito das leis existentes sobre transparência e das atribuições das ferramentas de participação social.

Palavras-Chave: Transparência. Controle Social. Lei de Acesso a Informação. Governo Eletrônico.

\begin{abstract}
This study aims to contribute to the debate on transparency and social participation of Brazilian public management, performing a critical analysis on the proposals made at the $1^{\text {st }}$ National Conference on Transparency and Social Control (Consocial) on its axis 1 . Through the analysis sought to identify whether the proposals made during the $1^{\text {st }}$ Consocial contributed to the exercise of social control based on transparency and access to information. The methodology used was exploratory and participatory research. Through the analysis of the proposals prioritized in the last step of the 1st Consocial observed the need for greater disclosure of information relating to public administration, the manifestation of the powers of the instruments of participation and empowerment of citizens to exercise participation. Some faults were detected in the formulation of proposals, such as the lack of participants regarding laws on transparency and the responsibilities of the tools of social participation.
\end{abstract}

Key-Words: Transparency. Social Control. Access to Information Act. Electronic Government.

\title{
1. INTRODUÇÃO
}

A administração pública tem sido alvo de controvérsias a respeito da transparência de seus atos. Em países democráticos, a transparência superficial - não tanto pela dotação de recursos, mas pela sua aplicabilidade - se transforma em fator altamente questionável pela sociedade, o que, em muitos casos, tornam ocultas as informações da gestão pública, comprometendo a credibilidade sobre a assertiva desses atos. A cobrança da sociedade por visibilidade está vinculada à necessidade de abrir acesso ao conteúdo informacional dos atos e gastos efetivados pelo governo. O conhecimento pleno daqueles atos, por si só, não atende às expectativas do cidadão, que, também, exige qualidade informacional, em espaço temporal. Uma sociedade participativa consciente da atuação dos seus representados desempenha, de forma mais satisfatória, o exercício da democracia quando tem o livre arbítrio de opinar e fiscalizar os gastos públicos.

Fraudes e atos de corrupção encontram oportunidades propícias para propagação em ambientes nos quais a gestão pública pode escamotear informações por julgá-las impróprias para o acesso generalizado. No Brasil, a Lei de Acesso à Informação, no 12.527, de 18 de novembro de 2011, busca tornar menos obscuro o conhecimento da informação por parte dos cidadãos, no que se refere à forma como os nossos recursos públicos são administrados. O acompanhamento dos recursos financeiros da gestão pública permite à sociedade civil exercer um papel fundamental na identificação de fraudes; suas ocorrências impedem o crescimento do país, solapando a legitimidade da gestão pública, fato que pode ocasionar uma redução do bem estar coletivo, em prol de interesses individuais, ocasionando a queda de sua imagem.

O advento da Internet singularizou a forma de divulgação dos dados da gestão pública, de maneira coletiva, ao abrir canais de acesso, cujos conteúdos se tornam, potencialmente, facilitadores da transparência no setor público, geradores de grande impacto na forma como essas instituições 
interagem com o seu ambiente e, em particular, com usuários de seus produtos e serviços. Essa interação contribui para a satisfação das necessidades dos usuários de seus produtos e serviços (MCIVOR; MCHUGH; CADDEN, 2002).

A população demanda informações referentes à gestão das finanças públicas e, conforme Slomski et al. (2010), o volume de recursos disponibilizados pela sociedade ao Estado, via tributação, justifica plenamente o estudo de formas de evidenciação que contribuam para a melhor transparência das informações, por meio de prestação de contas de maneira ampla e transparente, possibilitando avaliação sobre o desempenho dos gestores públicos. A sociedade deve participar no acompanhamento e controle da gestão pública, interagindo com o governo, podendo solicitar deste informações de seu interesse, a qualquer momento. Com este intuito, emergiu, por meio de decreto presidencial 1 do dia 8 de dezembro de 2010, a 1a Conferência Nacional sobre Transparência e Controle Social (Consocial).

A 1a Consocial propôs, como objetivo principal, promover a transparência do setor público e estimular a participação da sociedade no acompanhamento dos gastos governamentais. O tema central se fixou em: "A Sociedade no acompanhamento e controle da gestão pública" e foi desenvolvido por etapas preparatórias, em âmbito municipais, estaduais e nacional. A partir do resultado da 1a Consocial será feito uma análise crítica das 5 (cinco) propostas mais votadas no eixo 1 , promoção da transparência pública e acesso à informação e dados públicos.

Assim este estudo se justifica em razão de apresentar um assunto relacionado a transparências das informações públicas, dentre elas as informações contábeis. A convergência das Normas Contábeis Brasileiras às Normas Internacionais de Contabilidade Aplicadas ao Setor Público reafirmou a necessidade da adequação das entidades públicas em relação à divulgação de sua gestão, tornando-a mais transparente e com canais de interação com a sociedade. A Consocial visou obter a opinião da população sobre o que deve ser feito para auxiliar a sociedade no acompanhamento e controle da gestão pública.

Diante do exposto, pretende-se investigar o seguinte problema de pesquisa: Quais as possíveis contribuições das propostas aprovadas na Consocial, no eixo 1, para a promoção da transparência pública e acesso à informação e dados públicos?

\section{REFERENCIAL TEÓRICO}

\subsection{CONVERGÊNCIA DAS NORMAS CONTÁBEIS BRASILEIRAS ÀS NORMAS INTERNACIONAIS DE CONTABILIDADE APLICADAS AO SETOR PÚBLICO}

A convergência contribuiu para aproximar a sociedade do poder público. A contabilidade aplicada ao setor público adotava o orçamento como seu objeto. A sociedade na sua maioria não compreendia a contabilidade pública por meio do orçamento e sua execução. O principal interesse do cidadão consistia na evidenciação patrimonial, realizando o acompanhamento da evolução patrimonial e da aplicação da verba pública.

As alterações ocorreram pelo fato da contabilidade brasileira ter sido influenciada pelo dinamismo do mercado internacional, repercutindo em modificações na contabilidade da iniciativa privada. $O$ Conselho Federal de Contabilidade (CFC) criou o Comitê de Pronunciamentos Contábeis (CPC), órgão responsável pela convergência das Normas Brasileiras de Contabilidade para os padrões internacionais expedidos pelo colegiado de padrões internacionais, o International Accounting Standard Board (IASB). Uma das medidas adotadas pela contabilidade brasileira foi a publicação da Lei $\mathrm{n}^{\circ}$ 11.638/2007, conhecida como Nova Lei das Sociedades por Ações, que auxiliou o desenvolvimento do processo de adaptação às normas internacionais. 
O setor público, para adequar-se ao processo de convergência dos padrões internacionais, publicou a Portaria no 184/2008, do Ministério da Fazenda e as dez primeiras Normas Brasileiras de Contabilidade Aplicadas ao Setor Público (NBCAPS). Conselho Federal de Contabilidade (CFC) iniciou a publicação, em 2008, das primeiras Normas de Contabilidade Aplicadas ao Setor Público (NBC T 16) com o objetivo de padronizar as práticas contábeis brasileiras do setor público e iniciar a adoção dos padrões internacionais. As Normas de Contabilidade Aplicadas ao Setor Público advieram das Normas Internacionais Aplicadas ao Setor Público (International Public Sector Accounting Standards IPSAS), que têm como finalidade precípua dispor sobre as demonstrações contábeis do setor público.

A Controladoria Geral da União, a partir dessas recentes mudanças introduzidas pelas Normas de Contabilidade Aplicadas ao Setor Público, convocou a sociedade a participar da 1a Consocial com o objetivo principal de promover a transparência pública e de estimular a participação dela no acompanhamento e controle da gestão pública. A sociedade por meio dessa conferência pode participar formulando propostas/diretrizes que possam melhorar a transparência e controle social no setor público brasileiro. As mudanças introduzidas auxiliaram na obtenção de informações dos setores públicos e no exercício da participação social. O aumento da transparência pública traz benefícios sociais, pois permite um maior acompanhamento da gestão pública e do cumprimento das metas estabelecidas.

\title{
2.2.EVIDENCIAÇÃO
}

Como afirma Silva (2011), a contabilidade do setor público está apoiada em dois princípios: o princípio da evidenciação (artigos 83, 89 e 104 da Lei no 4.320/64) e o princípio da universalidade dos registros (artigos 93 e 100 da Lei no 4.320/64).

A evidenciação, também chamada pelo termo inglês de "disclosure", assume um papel de grande importância na contabilidade. ludícibus (2010, p. 115) a define como:

\begin{abstract}
Um compromisso inalienável da Contabilidade com seus usuários e com os próprios objetivos. As formas de evidenciação podem variar, mas a essência é sempre a mesma: apresentar informação quantitativa e qualitativa de maneira ordenada, deixando o menos possível para ficar de fora dos demonstrativos formais, a fim de propiciar uma base adequada de informação para o usuário.
\end{abstract}

A evidenciação busca colocar à disposição dos usuários informações relevantes e pertinentes. A disponibilidade dos dados permite a tomada de decisão das pessoas e o acompanhamento das ações realizadas. Atualmente, tem-se abordado o tema evidenciação no setor público com uma frequência maior, devido à adoção das normas internacionais. No entanto, verifica-se a existência de legislação abordando o tema no Brasil, como a Lei no 4.320/64, que já retratava a evidenciação nos relatórios contábeis do setor público.

\subsection{ACCOUNTABILITY}

A tradução do termo accountability é notoriamente imprecisa (MULGAN, 2000) e envolve responsabilidade (objetiva e subjetiva), controle, transparência, obrigação de prestação de contas, justificativas para as ações que foram ou deixaram de ser empreendidas, premiação e/ou castigo (PINHO, 2008). Para Bizerra (2011, p.45) existente uma interligação entre transparência e accountability:

Transparência e accountability são termos intimamente relacionados. A transparência é o meio pelo qual se pode gerar a accountability no setor público, pois não há como fazer com que haja responsabilização por parte dos gestores quando não é possível ter conhecimento por meio de informações claras sobre como os recursos foram utilizados e quais os resultados gerados em decorrência das políticas públicas adotadas. 
O accountability abrange um conjunto de medidas. A ausência de um dos procedimentos compromete a sua total aplicação. Segundo Matias-Pereira (2012) o termo reúne mecanismos e procedimentos que conduzem os dirigentes governamentais a prestar contas dos resultados de suas ações à sociedade, garantindo-se a divulgação das políticas públicas e o aumento do nível de transparência.

Outra forma de evidenciar a transparência é por meio do Governo Eletrônico. Vários entes públicos têm recorrido à tecnologia da informação para disponibilizar as informações exigidas pela Lei de Responsabilidade Fiscal (Lei Complementar $n^{\circ}$ 101/2000) e pela Lei de Acesso à Informação (Lei № 12.527/2011). Ele permite a informatização dos atos governamentais e o acesso público externo a estas informações. Como afirma Pinho (2008), a construção de portais governamentais é uma forma de descentralizar as informações, mostrando sua identidade, seus propósitos e suas realizações, além de permitir o aumento da transparência. O Governo Eletrônico apresenta-se basicamente como a disponibilização de informações e de serviços públicos aos cidadãos, facilitando a aplicabilidade do accountability e a participação social.

\subsection{PARTICIPAÇÃO SOCIAL}

A transparência estimula a participação social, a informação divulgada aproxima sociedade da gestão exercida por seus representantes. As entidades públicas têm o dever de promover a transparência de sua administração e a sociedade tem o direito ao acesso e o acompanhamento da administração pública, como forma de consolidação da cidadania.Segundo Jacobi (2003) para alcançar mudanças na participação social há a necessidade de transformações institucionais que garantam acessibilidade e transparência da gestão.

A transparência proporciona um ambiente de análise e reflexão, mas para isso é necessário que os gestores públicos descortinem suas tomadas de decisões e divulguem-nas livremente nos meios de comunicação acessíveis à população, não permitindo que suas informações fiquem restritas a alguns servidores e assessores. $\mathrm{O}$ aumento da transparência auxilia o envolvimento de diferentes classes sociais no acompanhamento da gestão. A divulgação para grupos restritos inibe o seu caráter de promoção da democracia, ferindo os princípios constitucionais da legalidade, impessoalidade, moralidade, publicidade e eficiência. Com isso, desenvolve-se um ambiente propício a condutas ilegais e corruptas.

A Constituição da República Federativa do Brasil de 1988 favoreceu a transparência, a adoção de práticas transparentes. O seu artigo 37 afirma que "a administração pública direta e indireta de qualquer dos Poderes da União, dos Estados, do Distrito Federal e dos Municípios obedecerá aos princípios da legalidade, impessoalidade, moralidade, publicidade e eficiência". Através da publicidade o povo poderá ter acesso às informações referentes aos atos praticados por seus representantes. A Constituição Federal de 1988 descentralizou a gestão das políticas públicas e sancionou a participação da sociedade civil nos processos de tomada de decisão (LUBAMBO; COUTINHO, 2004)

A Lei Complementar no 101, de 4 de maio de 2000, conhecida como Lei de Responsabilidade Fiscal (LRF) estabelece no seu parágrafo 1을 do artigo 1ㅇqu "a responsabilidade na gestão fiscal pressupõe a ação planejada e transparente, que se previnem riscos e corrigem desvios capazes de afetar o equilíbrio das contas". Limberger (2006) afirma que a LRF veio a disciplinar os gastos do administrador público e, ainda, a divulgar a ideia de transparência na gestão fiscal, como forma de conferir efetividade ao princípio da publicidade, norteador da administração pública. A LRF, com as alterações introduzidas pela Lei Complementar no 131/2009 no seu artigo 48, parágrafo único do inciso II, assegura a "liberação ao pleno conhecimento e acompanhamento da sociedade, em tempo real, de informações pormenorizadas sobre a execução orçamentária e financeira, em meios 
eletrônicos de acesso público". Para Sacramento e Pinho (2007), a LRF integra o rol das medidas que contribuem para o avanço formal da transparência na administração pública no Brasil.

Com o intuito de regulamentar o acesso a informações previstas no inciso XXXIII do artigo 5o, no inciso Il do parágrafo 3 ㅇ do artigo 37 e no parágrafo 2 ㅇ do artigo 216 da Constituição Federal, surge a Lei no 12.527 de 18 de novembro de 2011 que entrou em vigor 180 (cento e oitenta dias) após a data de sua publicação. Esta Lei regula o acesso a informações previstas na Constituição. A Lei destina assegurar o direito fundamental de acesso à informação e devem ser executados em conformidade com os princípios básicos da administração pública

A Lei no 12.527/2011, conhecida como Lei de Acesso a Informação

retrata o acesso e a divulgação da informação, bem como as restrições de acesso à informação. As legislações estão sendo criadas no intuito de fornecer mais transparência. Porém, para que o cidadão faça um bom uso da informação obtida, é necessário que ele a compreenda e tenha condição de realizar um juízo crítico sobre as mesmas.

O cidadão deve receber treinamento adequado, para que possa usufruir dos instrumentos de transparência disponíveis para sua consulta. Portanto, é importante capacitar o cidadão para o exercício do controle social. O processo de democratização da administração trouxe instituições voltadas para a participação social, proporcionando o intercâmbio entre governo e sociedade. Entre os mecanismos de participação social podemos citar: os conselhos de políticas públicas, observatório social, orçamento participativo, audiência pública e ouvidoria.

Os Conselhos de políticas públicas apresentam-se como um mecanismo de participação da sociedade civil na administração pública. Para Luchmann e Almeida (2010, p. 89) "os Conselhos são instâncias de discussão e deliberação de políticas públicas, amparadas por legislação nacional e que apresentam um desenho institucional estruturado e sistêmico, podendo atuar nas três esferas governamentais (município, estado e união)" com a finalidade de contribuírem para o controle social e constituem colegiados com função deliberativa ou consultiva (OLIVEIRA, 2009; CUNHA, 2011).

Verifica-se a necessidade do poder público apresentar a função dos conselhos de políticas públicas à sociedade, destacando suas atribuições, objetivos e finalidades. Quando os conselhos exercem seu papel de instrumento de participação possibilita um aumento na comunicação entre governantes e governados, sendo potenciais de formação de cidadãos mais atuantes.

O Observatório Social assim como os conselhos de políticas públicas é um mecanismo de controle social, promovendo a participação da sociedade nas políticas públicas locais. Entretanto, ao contrário dos conselhos o observatório é uma instituição totalmente independente (ONGs) do poder público. A criação dos observatórios sociais, como ferramenta de controle social, trata-se de um fato recente, assim como os conselhos de políticas públicas. Os observatórios surgiram como uma reação às forças neoliberais, permitindo um aumento da participação dos cidadãos na gestão dos recursos públicos.

Um observatório, ao monitorar sistematicamente as ações de certo setor ou órgão, ou tema de interesse coletivo ou ainda um território, exerce controle social e pode contribuir para avanços em accountability (ROSELL; RUIZ, 2008). Quando o observatório social é atuante e existe uma fiscalização social ativa, o próprio órgão público passa a repensar sua forma de gerir as verbas públicas. Por ter o entendimento que seus atos serão divulgados para a sociedade e para os órgãos de controle externo, a gestão, por consequência, tornará cada vez mais voltada para os fins sociais.

Como forma de transparência, é possível destacar também a sistemática do orçamento participativo que, sob o aspecto da transparência da gestão pública e do acesso por parte do cidadão é um instrumento positivo tendo em vista que é o início da futura execução, o que também se torna uma das formas precursoras de controle social e não apenas da expressão das necessidades sociais mais 
urgentes. O orçamento participativo (OP) apresenta-se como instrumento de participação social, permitindo que o poder público e o cidadão formulem a proposta orçamentária, tendo então uma atribuição do poder executivo compartilhada com a sociedade, o que valoriza o debate e enriquece as escolhas com o lastro da sociedade assistida.

O orçamento participativo consiste numa nova forma de planejar os gastos públicos. O orçamento é elaborado com a participação de indivíduos de diferentes classes sociais, promovendo a destinação da verba pública em projetos e atividades do interesse da coletividade. Assim como a audiência pública o orçamento participativo permite que o cidadão seja ouvido antes da realização do ato administrativo, discutindo o planejamento das receitas e despesas. A audiência pública, assim como o observatório social, apresenta-se como instrumento de controle social, na qual a sociedade interage com o poder público para decidir determinada questão. Segundo Carvalho Filho (2005 p. 192), "a audiência pública é a forma de participação popular pela qual determinada questão relevante, objeto de processo administrativo, é sujeita a debate público e pessoal por pessoas físicas ou representantes de entidades da sociedade civil".

Outro exemplo de participação social é a ouvidoria pública que permite a comunicação entre governantes e governados, contribuindo, assim, para um maior acesso a informação e, sobretudo, à busca de transparência da gestão. Para Cardoso (2010), a ouvidoria pública, enquanto instrumento de inclusão social, é um poderoso instrumento de controle social pela relação direta entre inclusão e controle social. A Ouvidoria busca dar a transparência devida a gestão pública, com a participação dos cidadãos na melhoria dos serviços públicos prestados e na avaliação das políticas públicas.

\section{METODOLOGIA}

Este estudo apresenta como metodologia quanto ao seu objetivo como uma pesquisa exploratória sendo realizada em área na qual há pouco ou nenhum conhecimento anterior em que possamos buscar informações sobre o problema (COLLIS; HUSSEY, 2005). Para sua realização utilizou-se uma pesquisa participante para Silva (2003) a pesquisa participante é desenvolvida a partir da integração entre pesquisador e pessoas relacionadas ao problema investigado, eliminando a distância existente entre pesquisador e pesquisado.

A pesquisa participativa retrata as etapas da pesquisa no momento de sua ocorrência, permitindo alcançar detalhes e a visão privilegiada do pesquisador, que funciona como membro integrante do grupo analisado. Neste tipo de pesquisa, há um envolvimento da pessoa que realiza a pesquisa e o pesquisado. A população conhece o problema e busca a sua solução. A produção das possíveis soluções é desenvolvida em grupo com a participação do pesquisador. Esse tipo de pesquisa produz um grande envolvimento e interesse dos pesquisados, pois os mesmos visam a alcançar um resultado que resolva o problema identificado.

Realizou-se um estudo exploratório descritivo, com o objetivo de identificar e obter informações sobre as características de um determinado problema ou questão. Consiste em uma pesquisa qualitativa, mais subjetiva e envolve examinar e refletir as percepções para obter um entendimento de atividades sociais e humanas (COLLIS; HUSSEY, 2005).

A pesquisa exploratória foi realizada nos sites relacionados ao tema pesquisa, livros, dissertações e sites. Foi realizada observação direta em alguns congressos e a participação nos fóruns de discussão para a formulação de propostas, voltadas para a obtenção de uma maior transparência pública.

A participação na elaboração de propostas na Consocial na etapa municipal, nos municípios de Macaé no eixo 1, Rio de Janeiro eixo 4, Niterói - Mangaratiba eixo 2, na conferência livre do Conselho Regional de Contabilidade(CRC), Conferência do Estado do Rio de Janeiro e na conferência virtual permitiu o acompanhamento e a sugestão de ideias para as propostas. A conferência virtual permitiu a formulação de propostas via internet; os participantes poderiam sugerir propostas, 
realizar sugestões de melhorias e adaptações no texto. 0 fato dos debates terem sido realizados entre os dias 19 de março a 8 de abril de 2012 contribuiu para o estudo mais detalhado; as ideias contaram com um tempo maior para serem desenvolvidas, ocorrendo, por esse motivo, discussões mais aprofundadas sobre o tema.

\section{ANÁLISE CRÍTICA DAS PROPOSTAS DO EIXO 1 DA la CONSOCIAL}

$\mathrm{Na}$ etapa nacional da Consocial foram priorizadas 40 propostas mais votadas, sendo 10 de cada Eixo Temático. Nesta seção serão analisadas as 07 (sete) propostas mais votadas no eixo temático 1 Promoção da transparência pública e acesso à informação e dados públicos.

Quadro 1: Proposta 01

\section{PROPOSTA 1}

Regulamentar, em todos os níveis da Federação, que toda e qualquer publicação de dados públicos na web seja em formato aberto, definindo planos anuais com cronogramas, aspectos técnicos, responsabilidades, indicadores e metas de abertura de dados, para facilitar sua obtenção, análise e reaproveitamento pela sociedade (com investimento em centros para análise desses dados), de maneira que sejam mais legíveis para pessoas leigas. Para isso, pode-se desenvolver e implantar um programa de capacitação (envolvendo aspectos de sensibilização, filosóficos, técnicos e gerenciais) para os servidores públicos sobre dados abertos, em parceria com universidades e ONGs; tornar obrigatório que órgãos públicos criem grupos de trabalho ou departamentos com competência sobre dados abertos, responsáveis por criar programas, campanhas e identificar, em parceria com a sociedade, as demandas por dados abertos...

Fonte: Consocial (2012)

Esta proposta foi a mais votada no eixo 1 recebendo 256 (duzentos e cinquenta e seis) votos e há sugestões já amparadas pela Lei no 12.527/2011 como afirma seu artigo 8 “os sítios deverão, através de regulamento, conter ferramenta de pesquisa de conteúdo que permita o acesso à informação de forma objetiva, transparente, clara e em linguagem de fácil compreensão". Consta nesta mesma lei que os sítios devem possibilitar a gravação de relatórios em diversos formatos eletrônicos, inclusive abertos e não proprietários, assim como conceder o acesso automatizado por sistemas externos, estruturados e legíveis por máquina. Os órgãos responsáveis devem garantir a autenticidade, a integridade e a atualização das informações disponíveis para acesso.

A proposta aponta uma deficiência existente na falta de regulamentação dos prazos relacionados à divulgação das informações. O cronograma orientaria as pesquisas realizadas pela sociedade. Os órgãos, ao disponibilizarem as informações desatualizadas, estão comprometendo o entendimento a respeito da situação real da administração, não demonstrando a gestão em tempo real. Uma informação de meses atrás não tem a mesma utilidade da informação de semanas ou do mês anterior. A transparência dos dados precisa também seguir uma sequencia lógica para auxiliar o entendimento dos leitores.

A legislação retrata a competência dos poderes em dar transparência, mas não estabelece os setores responsáveis pela divulgação dos dados, expondo suas atribuições e a qual órgão recorrer em caso de dúvidas e esclarecimentos. As entidades públicas precisam definir junto aos tribunais de contas os setores escolhidos para tal responsabilidade. Devem ficar claras as competências, tendo em vista que o tema transparência não era totalmente adotado no momento da elaboração dos regimentos internos dessas entidades.

Outro ponto sugerido na proposta foi a criação de programas com a finalidade de capacitar agentes públicos. A Lei no 12.527/2011 já prevê no seu artigo 41 o desenvolvimento do programa de capacitação dos agentes públicos nas práticas relacionadas à transparência na administração pública. Os participantes deveriam receber um treinamento a respeito da Lei de acesso à informação antes de sua participação nos debates da Consocial. Assim as propostas estariam mais próximas das reais 
necessidades brasileiras. A Lei já obriga a criação desses programas de capacitação. A proposta poderia sugerir uma cobrança e penalidade para os órgãos que não cumprissem, efetivamente, as exigências legais. Por isso faz-se necessário fixar o mínimo de transparência aceitável e quais as principais informações a serem divulgadas. A proposta sugere também que os repasses sejam vinculados ao cumprimento da divulgação dos dados. Como por exemplo, nos repasses dos impostos estaduais aos municípios existir a exigência das prefeituras divulgarem, mensalmente, as suas arrecadações próprias e as medidas empregadas para ampliar suas receitas.

A ideia de criar incentivos fiscais no setor público, para que organizações da sociedade civil, institutos de pesquisa e empresas da iniciativa privada, especializadas em Tecnologia da Informação, desenvolvam soluções e aplicativos para dados abertos públicos é pertinente, mas precisa levar em conta que essa medida poderia beneficiar organizações de má fé. A sugestão mais aplicável seria adotar a modalidade de licitação/concurso entre quaisquer interessados para escolha de trabalho técnico, científico ou artístico, mediante a instituição de prêmios ou remuneração aos vencedores. A avaliação dos vencedores precisa ser realizada por especialistas na área da tecnologia da informação, professores universitários e representantes do Serviço Federal de Processamento de Dados. Dessa forma, conseguiriam sugestões sem comprometer a legislação tributária.

Quadro 2: Proposta 02

\section{PROPOSTAS 2:}

Criar a obrigatoriedade de o governo praticar licitações abertas, por meio da atualização da Lei de Licitações (no 8.666/93), incluindo a obrigatoriedade de "divulgação de todos os editais e processos licitatórios"; das compras diretas feitas com empresas pelos órgãos públicos (das esferas federal, estadual e municipal), de concessionárias de serviços públicos e demais instituições envolvidas em processos de contratação com o setor público, nos sítios eletrônicos oficiais (além de rádio, televisão e jornais locais), em tempo real, para melhor acompanhamento da sociedade civil e para evitar fraudes e favorecimentos...

Fonte: Consocial (2012)

Com 225 (duzentos e vinte e cinco) votos, a segunda proposta sugere alterações na Lei de Licitações, lei que regulamenta o artigo 37, inciso XXI da Constituição Federal de 1988, institui normas para licitações e contratos da administração pública. Sobre esse tema há um debate virtual no site edemocracia da Câmara dos Deputados. O objetivo do fórum consiste na discussão com a sociedade no intuito de aprimorar a lei de licitações e contratos da Administração Pública (Lei no 8.666/93). Uma licitação mais transparente, com a divulgação de suas etapas, incentiva a participação de novos interessados que terão acesso às informações pertinentes ao processo licitatório, diminuindo a probabilidade de favoritismo. Possibilita, também, uma maior participação do cidadão na gestão da despesa pública, permitindo um acompanhamento detalhado da destinação das receitas publicas.

O aumento da divulgação das licitações traz benefícios econômicos, sociais e avalia a sua economicidade. Uma licitação restrita a um pequeno grupo de participantes não proporciona uma real competição entre os licitantes, revelando uma alternância de vencedores em diferentes licitações e uma prévia combinação dos valores das propostas. Em alguns casos, a entidade escolhe o fornecedor A e este fica encarregado de selecionar outros participantes com propostas superiores a sua, figurando uma licitação com vícios e distante dos objetivos de garantir a observância do princípio da isonomia e a seleção da proposta mais vantajosa para a administração pública.

A divulgação da licitação, seu procedimento e julgamento favorece a participação de fornecedores de diferentes localidades, ampliando a competição entre eles. Muitas prefeituras restringem a divulgação do edital apenas em sua cidade, não permitindo que fornecedores de outros municípios participem no intuito de beneficiar a economia local, quando o objetivo primordial consiste na economicidade do processo. A sugestão da criação do cadastro nacional dos participantes de processos licitatórios na internet, com os respectivos dados societários, discriminados por categorias 
de atuação pré-estabelecidas auxiliaria o acompanhamento das empresas vencedoras de licitação. Isso evitaria que empresas fossem criadas exclusivamente para negociar com órgãos públicos, tendo sócios ligados a gestores e servidores.

A proposta aponta a necessidade de disponibilizar um Sistema Eletrônico de Compras que possibilite o acesso, em tempo real, do desenvolvimento de todo o processo de compras públicas. No site do Banco do Brasil, há o acompanhamento de algumas licitações publicadas, com propostas abertas, em disputa, em homologação e as concluídas. Essa iniciativa do Banco do Brasil foi para atrair um maior número de participantes. O site auxilia fornecedores e cidadãos no acompanhamento das licitações. Essa iniciativa deveria ser obrigatória a todos os entes públicos.

Os participantes identificaram a ausência da devida capacitação dos representantes da sociedade civil organizada como multiplicadores nos processos licitatórios. Essa tarefa poderia ser realizada com a contribuição dos Observatórios Sociais. O trabalho dos Observatórios Sociais auxilia no acompanhamento do processo licitatório. A difusão da adoção desse instrumento de participação social nos municípios, acompanhado do aumento de transparência, traria melhorias ainda mais significativas. O observatório social acompanha a gestão dos recursos públicos com o objetivo de alcançar uma melhor aplicação. Como se trata de um órgão independente, este realiza sua fiscalização junto ao poder público, voltado para a necessidade da sociedade civil.O observatório verifica a entrega do material licitado e da prestação do serviço, contribuindo para uma licitação transparente e processada e julgada em estreita conformidade com os princípios básicos da legalidade, da impessoalidade, da moralidade, da igualdade, da publicidade, da probidade administrativa, da vinculação ao instrumento convocatório, do julgamento objetivo.

Quadro 3: Proposta 03

PROPOSTAS 3:

VOTOS

Transparência no Judiciário, com reforma no setor e obrigatoriedade na divulgação da prestação de contas, da carga e fluxo de trabalho, produtividade de Magistrados e servidores do Poder 206 Judiciário, em tempo real, na internet, e em outros meios de comunicação.

Fonte: Consocial (2012)

Com 206 (duzentos e seis) votos essa proposta diz respeito à transparência no Poder Judiciário. 0 poder judiciário está subordinado à Lei № 12.527/2011, conforme afirma o artigo 1으 no parágrafo único inciso I os órgãos públicos integrantes da administração direta dos Poderes Executivo, Legislativo, incluindo as Cortes de Contas, e Judiciário e do Ministério Público. O Poder Judiciário tem como missão fortalecer o Estado Democrático e contribuir para a construção de uma sociedade livre, justa e solidária. No entanto, o judiciário não está imune à gestão fraudulenta.

O caso do juiz Nicolau dos Santos Neto que desviou recursos da obra do Tribunal Regional do Trabalho (TRT/SP) de São Paulo é um exemplo da falta de controle e fiscalização no Poder Judiciário. Nicolau montou um esquema para facilitar a liberação do dinheiro desviado, contando com a participação de empreiteiros, senador e diretor. A apuração dos fatos foi realizada por meio de investigação e da CPI do judiciário.

A proposta aponta a necessidade de transparência em relação às entradas e saídas de recursos públicos, ao questionar maior transparência nas prestações de contas do poder judiciário, assim como à jornada de trabalho dos Magistrados e servidores do Poder Judiciário. O Judiciário não pode ser visto como um Poder acima da lei nas questões relacionadas à transparência nas prestações de contas, jornada de trabalho e produtividade. Assim como nos demais Poderes a sociedade requer também do Judiciário transparência na sua administração tanto financeira como relacionada ao tempo destinado ao cumprimento de seu trabalho. 
Criar e fortalecer ouvidorias públicas municipais, estaduais e federais abrangentes a todos os setores públicos, com ampla divulgação do telefone tridígitos, 0800, "site" e "e-mail", com ferramentas para acessibilidade a pessoas com deficiência. As ouvidorias devem facilitar o acesso da população para a realização de denúncias, críticas, informações e esclarecimentos a fim de fortalecer canais de comunicação entre o poder público e a sociedade. As ouvidorias devem subsidiar o controle interno e, portanto, devem estar articuladas às atividades do sistema interno a que faz referência o artigo 74, essenciais ao funcionamento da administração pública.

Fonte: Consocial (2012)

Com 199 (cento e noventa e nove) votos a quarta proposta retrata a necessidade de um canal de ligação da sociedade com o poder público. Nos últimos anos, houve um aumento do número de ouvidorias no setor público. O cidadão encontra nas ouvidorias a oportunidade de expor suas críticas e indagações. Apresentam-se como um canal de ligação da sociedade com o poder público. 0 fortalecimento da ouvidoria como órgão autônomo contribui para diminuir a influência política sobre esse órgão, minimizando a possibilidade do órgão servir apenas como coletor das demandas dos membros da sociedade.

As ouvidorias apresentam-se com o canal de participação social mais acessível ao cidadão, pois a comunicação com a ouvidoria independe deste estar representando uma classe, no caso de presidente de associação de moradores ou agindo em causa própria. O cidadão, ao realizar reclamações junto às ouvidorias, contribui para avaliar a gestão pública. As reclamações contribuem para a adoção de melhorias nos serviços prestados. A ouvidoria não é apenas um receptor de reclamações sua função abrange a busca de soluções. Na proposta sugere que a ouvidoria auxilie o controle interno nas suas atividades. As informações levantadas pelas ouvidorias poderiam ser utilizadas nos trabalhos executados pelo controle interno. Os pareceres de auditorias deveriam expor a estatística de reclamação dos setores juntamente com as medidas sugeridas pelos auditores internos para a solução dos problemas.

Quadro 5: Proposta 05

\section{PROPOSTA 5:}

VOTOS

Regulamentação e padronização de normas técnicas para a elaboração e o acompanhamento dos planos de governo, que devem ser apresentados pelos candidatos eleitos, bem como seus desdobramentos e divulgação em planos de metas com as quais se comprometa até o final de seu mandato, organizados com indicadores e metas que deverão orientar e alinhar a elaboração dos Planos Plurianuais (PPAs), das Leis de Diretrizes Orçamentárias (LDOs) e das Leis Orçamentárias Anuais (LOAs)...

Fonte: Consocial (2012)

Esta proposta recebeu 180 (cento e oitenta) votos e revela que a sociedade almeja a transparência dos planos e projetos dos candidatos eleitos antes da publicação do Plano Plurianual, Lei de Diretrizes Orçamentárias e da Lei Orçamentária Anual. 0 acompanhamento da proposta de governo antes da divulgação das leis permite uma avaliação prévia da gestão a ser implantada. Esses instrumentos constitucionais de planejamento presentes no artigo 165 da Constituição Federal/1988 estão vinculados entre si; a Lei Orçamentária Anual (LOA) deve estar compatível com o Plano Plurianual (PPA) e sua elaboração será orientada pela Lei de Diretrizes Orçamentárias (LDO).

A sociedade não pode se contentar apenas com a informação das propostas governamentais. Ela precisa estar envolvida na formulação do orçamento participativo. 0 maior número de pessoas envolvidas trará benefícios no que diz respeito à eficiência e à eficácia do Orçamento Participativo (OP) como ferramenta de participação social. A proposta 
sugere também a inclusão da obrigatoriedade da transparência dos custos incorridos nos serviços e nas unidades administrativas. A previsão do controle do custo público não é algo novo na legislação brasileira; antes da adoção das normas internacionais já havia sua previsão. Porém, a sua divulgação não faz parte da realidade de muitos Estados e Municípios.

A Resolução do CFC no 1.366/11 veio ratificar a obrigatoriedade da apuração do custo no setor público. No seu item 4, afirma que "a evidenciação dos objetos de custos pode ser efetuada sob a ótica institucional, funcional e programática". A transparência dos custos incorridos favorece a análise mais detalhada das aplicações dos recursos públicos. O cidadão pode verificar se o valor foi bem empregado, se o gestor atendeu as prioridades do governo ou se os custos estão superiores aos benefícios proporcionados.

Quadro 6: Proposta 06

Criação de conselhos de Transparência Pública e Controle Social em âmbitos municipal, estadual, nacional e em órgãos públicos com garantia de recursos para seu funcionamento; de caráter consultivo e deliberativo; trabalhando em conjunto no planejamento, definição, fiscalização e controle da gestão da informação pública das três esferas de poder (Executivo, Legislativo e Judiciário), para fiscalização e controle dos recursos públicos/prestações de contas; combate à corrupção; investigação, análise de implantação de convênios, parcerias e repasses com ente público ou privado; que possam receber e encaminhar denúncias. O conselho deve ser formado: participação de $60 \%$ da sociedade civil, $30 \%$ de conselhos de políticas públicas e $10 \%$ do poder público.

Fonte: Consocial (2012)

Os 140 (cento e quarenta) votos dos delegados na 1a Consocial para esta proposta destacam que os Conselhos de Transparência Pública e Controle Social podem contribuir para o constante acompanhamento da gestão no que diz respeito a sua transparência e na avaliação dos canais disponibilizados para a interação entre sociedade e poder público. As competências desses conselhos não podem assumir o papel dos Tribunais de Contas. Os seus objetivos principais precisam consistir no controle da gestão da informação pública, verificando se os órgãos estão cumprindo a Legislação vigente e enviando denúncias para o CGU ou Tribunal de Contas, no caso de identificação de irregularidades.

Esses tipos de conselhos precisam realizar um trabalho com o objetivo de preparar o cidadão para o exercício do controle social. Como a realização de eventos, reuniões, seminários com o intuito de transmitir informações a respeito da transparência pública. A sociedade necessita ser instruída sobre a existência de leis sobre o livre acesso às informações públicas, bem como incentivar a participação da sociedade nos instrumentos de participação social.

Quadro 7: Proposta 07

Todas as esferas do poder público devem realizar audiências públicas sobre uma reforma tributária e fiscal progressiva e implementar uma efetiva prestação de contas, participação no planejamento orçamentário, elaboração do PPA, reajustes das tarifas de serviços públicos (água, luz, transporte, IPTU), distribuição de recursos, com discussões/avaliações da aplicação dos mesmos, procedimentos licitatórios com auditorias, assim como controle público das irregularidades, denúncias e punições a entes corruptos, prestações de contas de órgãos que lidam com questões indígenas, quilombolas e de comunidades tradicionais. As audiências devem se realizar periodicamente. Estas audiências devem ocorrer em dias e horários que facilitem a participação popular, com ampla divulgação prévia da assembleia e de suas pautas em linguagem acessível, envolvendo campanhas de conscientização por meio da internet e outros veículos. Devem-se criar meios legais de participação obrigatória de membros do Legislativo e organizações ou representantes da sociedade civil nas audiências.

Fonte: Consocial (2012) 
Os 116 (cento e dezesseis) votos elegeram esta proposta que aponta a necessidade de todas as esferas do poder público utilizar a audiência pública na reforma tributária e fiscal progressiva. Para a realização de uma reforma tributária, não basta apenas a existência de audiência pública tratando sobre o tema, requer, também, a implantação de outras medidas legais. Como alterações na legislação tributária municipal, estadual e federal e a aprovação das mudanças pelo poder legislativo.

A divulgação da realização das futuras audiências públicas é essencial. A participação da sociedade nos debates realizados traz resultados mais próximos das necessidades da população. As datas e horários, ao ficarem restritas a um reduzido número de pessoas, prejudicam a participação dos interessados e ferem a finalidade deste importante instrumento de debate da sociedade com o poder público.

\section{CONSIDERAÇÕES FINAIS}

A contabilidade pública inicia uma série de mudanças e uma delas é a transparência da informação contábil. As entidades públicas precisam estar preparadas para se adequar às novas exigências e o cidadão apto a acompanhar e a participar da gestão pública. $O$ controle social não é um assunto novo. Entretanto a maioria da sociedade desconhece os instrumentos de participação social. Há vários instrumentos de participação social, como conselhos de políticas públicas, observatório social, orçamento participativo, ouvidoria e audiências públicas. Esses mecanismos de aproximação do cidadão com o poder público, ainda não são totalmente conhecidos pela sociedade.

O processo de conscientização da sociedade quanto à importância da população utilizar os instrumentos de participação é um processo de longo prazo. Diversas medidas precisam ser implantadas para o atingimento de melhorias neste cenário. Os diversos segmentos sociais necessitam ser alcançados para a obtenção da participação de uma amostra significativa da população. Os programas voltados para a educação fiscal precisa se tornar uma realidade nas escolas e universidades brasileiras, introduzindo os conceitos sobre transparência e controle social na educação do país.

A 1a Consocial figurou-se como uma introdução a mobilizações em nível municipal, estadual e federal no que diz respeito à transparência e controle social. A conferência contribuiu para iniciar o cidadão nos debates. A primeira Consocial foi um passo importante na busca da interação entre sociedade e poder público com o propósito de uma melhoria na condução da transparência pública e no desenvolvimento dos canais de participação.

Algumas das propostas refletem a necessidade dos participantes em terem bem definidos os órgãos que devem recorrer quando as determinações legais relacionados a transparência da informação pública não são cumpridas pelas entidades. Assim como regulamentação dos prazos relacionados à divulgação das informações com o cronograma preestabelecido, facilitando o acompanhamento das publicações.

A sociedade destaca a necessidade de ampliação dos veículos de divulgação das informações públicas. As propostas deram contribuição para a melhoria da promoção da transparência e acesso a informação, entretanto essa colaboração poderia ser aprimorada com a capacitação prévia dos participantes.

Verificou-se, em algumas propostas, a falta de conhecimento prévio dos participantes sobre os assuntos abordados na conferência, ressaltando a ausência de uma etapa preparatória com a realização de seminários, reuniões, palestras explicativas e eventos culturais sobre o tema transparência e controle social. Essas reuniões poderiam ser realizadas nos bairros, nas associações de moradores ou em reuniões itinerantes. O poder público precisa capacitar o cidadão, fornecendo informações relevantes a respeito da gestão pública, mobilizando a sociedade para o pleno exercício da participação social. A falta de informação, no que diz respeito à legislação existente e aos 
instrumentos de participação social atualmente em vigor, restringe a elaboração de propostas mais precisas nas necessidades sociais.

Foram elaboradas propostas no eixo 1 aplicáveis ao eixo 4 ao tratar de combate à corrupção. Não ficou claro, para os participantes, a divisão dos eixos. Os mediadores das reuniões teriam que intervir para evitar os desvios nas discussões nos eixos. A sociedade precisa de mais treinamentos, novos fóruns de discussões sobre o tema "transparência e participação social". O eixo 1 foi escolhido por tratar do aumento do acesso aos dados públicos, assunto este de grande importância para a contabilidade pública. A divulgação das informações contábeis não atenderá somente à Lei de Responsabilidade Fiscal e aos órgãos fiscalizadores. Qualquer interessado poderá apresentar pedido de acesso a informações aos órgãos e entidades da administração pública.

Como se tratou do primeiro evento desse porte, espera-se que a experiência vivida conduza ao aperfeiçoamento nas edições seguintes. Para as futuras edições da Consocial, faz-se necessário uma maior divulgação e aumento do número de pessoas envolvidas. Um dos pontos principais a ser trabalhado para alcançar uma participação maior da sociedade nas questões governamentais consiste no ensino das crianças e jovens sobre a importância de se exigir transparência dos dados públicos e a busca por espaço nos instrumentos de participação. A Lei da transparência atenderá seus objetivos, na medida em que o cidadão tenha a consciência do seu papel primordial na busca e no acompanhamento da informação.

O relatório final da conferência relata que a Comissão Organizadora Nacional, por meio de sua Presidência - a Controladoria-Geral da União -, encaminhará o relatório final da 1 ạ Consocial em versão impressa, a autoridades públicas de todos os Poderes. Há a previsão da elaboração do Plano Nacional de Transparência e Controle Social que deverá ser construído com base nas deliberações da 1a Conferência Nacional sobre Transparência e Controle Social, mas também contemplar as orientações das políticas públicas voltadas para essas áreas, de forma coordenada e estratégica. Neste plano serão apresentadas as diretrizes relacionadas à promoção da transparência e a participação do cidadão na gestão pública.

\section{REFERÊNCIAS}

BIZERRA, A. L. V. Governança no setor público: a aderência dos relatórios de gestão do Poder Executivo municipal aos princípios e padrões de boas práticas de governança. 2011. 124f. Dissertação (Mestrado em Ciências Contábeis) - Faculdade de Administração e Finanças, Universidade do Estado do Rio de Janeiro, Rio de Janeiro, 2011.

BRASIL. Lei n. 4.320, de 17 de março de 1964. Estatui Normas Gerais de Direito Financeiro para elaboração e contrôle dos orçamentos e balanços da União, dos Estados, dos Municípios e do Distrito Federal. Diário Oficial da União, Brasília, DF, 23 mar. 1964. Disponível em: <http://www.planalto.gov.br/ccivil_03/leis/14320.htm>. Acesso em: 01 mar. 2012.

BRASIL. Constituição da República Federativa do Brasil de 1988. Diário Oficial da União, Brasília, DF, 5 out. 1988. Disponível em: <http://www.planalto.gov.br/ccivil_03/constituicao/constituicao.htm>. Acesso em: 01 mar. 2012.

BRASIL. Lei n. 8.666, de 21 de junho de 1993. Regulamenta o art. 37, inciso XXI, da Constituição Federal, institui normas para licitações e contratos da Administração Pública e dá outras providências. Diário Oficial da União, Brasília, DF, 22 jun. 1993, republicado em 6 jul. 1994 e retificado em jul. 1994. Disponível em: <http://www.planalto.gov.br/ ccivil_03 /leis//8666cons.htm>. Acesso em: 10 abr. 2012.

BRASIL. Lei Complementar n. 101, de 4 de maio de 2000. Estabelece normas de finanças públicas voltadas para a responsabilidade na gestão fiscal e dá outras providências. Diário Oficial da União, 
Brasília, DF, 5 maio 2000. Disponível em:< http://www.planalto.gov.br/ccivil_03/leis/lcp/lcp101.htm> Acesso em: 01 mar. 2012.

BRASIL. Lei n. 11.638, de 28 de dezembro de 2007. Altera e revoga dispositivos da Lei no 6.404 , de 15 de dezembro de 1976, e da Lei no 6.385, de 7 de dezembro de 1976, e estende às sociedades de grande porte disposições relativas à elaboração e divulgação de demonstrações financeiras. Diário Oficial da União, Brasília, DF, 28 dez. 2007, edição extra. Disponível em:< http://www.planalto.gov.br /ccivil_03/_ato2007-2010/2007/lei/ I11638.htm>. Acesso em: 01 mar. 2012.

BRASIL. Portaria n. 184, de 25 de agosto de 2008. Dispõe sobre as diretrizes a serem observadas no setor público (pelos entes públicos) quanto aos procedimentos, práticas, laboração e divulgação das demonstrações contábeis, de forma a torná-los convergentes com as Normas Internacionais de Contabilidade Aplicadas ao Setor Público. Diário Oficial da União, Brasília, DF, 26 ago. 2008. Disponível em: < http://www.fazenda.gov.br/institucional/legislacao/2008/portaria184>. Acesso em: 01 mar. 2012.

BRASIL. Lei Complementar n. 131, de 27 de maio de 2009. Acrescenta dispositivos à Lei Complementar no 101 , de 4 de maio de 2000, que estabelece normas de finanças públicas voltadas para a responsabilidade na gestão fiscal e dá outras providências, a fim de determinar a disponibilização, em tempo real, de informações pormenorizadas sobre a execução orçamentária e financeira da União, dos Estados, do Distrito Federal e dos Municípios. Diário Oficial da União, Brasília, DF, 28 maio 2009. Disponível em: <http://www.planalto.gov.br/ccivil_03/leis/lcp/lcp131. htm>. Acesso em: 01 mar. 2012.

BRASIL. Lei n. 12.527, 18 de novembro de 2011. Regula o acesso a informações previsto no inciso XXXIII do art. 5o, no inciso II do § 30 do art. 37 e no § 20 do art. 216 da Constituição Federal; altera a Lei no 8.112, de 11 de dezembro de 1990; revoga a Lei no 11.111 , de 5 de maio de 2005, e dispositivos da Lei no 8.159, de 8 de janeiro de 1991; e dá outras providências. Diário Oficial da União, Brasília, DF, 18 nov. 2011. Edição Extra. Disponível em: <http://www.planalto.gov.br/ ccivil_03/_ato2011-2014/2011/lei/l12527.htm>. Acesso em: 01 mar. 2012.

BRASIL. Decreto de 8 de julho de 2011. Convoca a 1a Conferência Nacional sobre Transparência e Controle Social - CONSOCIAL e revoga o Decreto de 8 de dezembro de 2010. Diário Oficial da União, Brasília, DF, 11 jul. 2011. Disponível em: <http://www.planalto.gov.br/ccivil_03/_Ato20112014/2011/Dsn/Dsn13078.htm\#art8>. Acesso em: 01 mar. 2012.

CARDOSO, A. S. R. Ouvidoria pública como instrumento de mudança. Instituto de Pesquisa Econômica Aplicada. 2010

CARVALHO FILHO, J. S. Processo administrativo federal: comentários à Lei n. 9.784, de 29/01/1999. 2 ed. Lumen Juris: Rio de Janeiro, 2005

COLLIS, Jill; HUSSEY, Roger. Pesquisa em administração: um guia prático para alunos de graduação e pós-graduação. 2 ed. Porto Alegre: Bookman, 2005.

CONSELHO FEDERAL DE COTABILIDADE (CFC). Resolução do CFC n. 1.366, de 25 de novembro de 2011. Aprova a NBC T 16.11 - Sistema de Informação de Custos do Setor Público. Diário Oficial da União, Brasília, DF, 02 dez. 2011. Disponível em: < http://www.cfc.org.br/sisweb/sre/detalhes_sre. aspx? codigo=2011/001366>. Acesso em: 12 mar. 2013.

CUNHA, E. S. M. Conselhos de políticas: possibilidades limites no controle público da corrupção. Cadernos Adenauer, Rio de Janeiro, v. XII, n. 3, 2011.

IUDÍCIBUS, S. Teoria da contabilidade. 10 ed. Atlas: São Paulo, 2010.

JACOBI, P. Educação ambiental, cidadania e sustentabilidade. Cadernos de Pesquisa, n.118, p. 189206, mar. 2003. 
LIMBERGER, T. Transparência administrativa e novas tecnologias: o dever de publicidade, o direito a ser informado e o princípio democrático. Interesse Público, Porto Alegre, v. 8, n. 39, p. 55-71, set./out. 2006.

LUBAMBO, C. W.; COUTINHO, H. G. Conselhos gestores e o processo de descentralização. São Paulo em Perspectiva, v.18, n.4, p. 62-72, 2004.

LUCHMANN, L. H. H.; ALMEIDA, C. C. R.. A representação política das mulheres nos Conselhos Gestores de Políticas Públicas. Revista Katálysis, v.13, n.1, p. 86-94, 2010.

MATIAS-PEREIRA, J. Manual de gestão pública contemporânea. 4 ed. São Paulo: Atlas, 2012.

MCIVOR, R.; MCHUGH, M.; CADDEN, C. Internet technologies: supporting transparency in the public sector. International Journal of Public Sector Management, v. 15, n. 3, p.170 - 187, 2002.

MULGAN, R. Comparing accountability in the public and private sectors. Australian Journal of Public Administration, v. 59, n.1, p. 87-97, March, 2000.

OLIVEIRA, V. C. S. Sociedade, Estado e administração pública: análise da configuração institucional dos conselhos gestores do município de Lavras-MG. 2009. 301 p. Tese (Doutorado em Administração) - Universidade Federal de Lavras, Lavras-MG, 2009.

PINHO, J. A. G. Investigando portais de governo eletrônico de estados no Brasil: muita tecnologia, pouca democracia. Revista de administração Pública, Rio de Janeiro, ano 42, n.3, p.471-493, maio/jun. 2008.

ROSELL, M. M. R.; RUIZ, B. C. Los observatorios como agentes mediadores en la responsabilidad social de los médios de comunicación: panorama internacional. Revista de Ciencias Sociales y de la Comunicación, n.8, p. 15-40, 2008.

SACRAMENTO, A. R. S.; PINHO, J. A. G. Transparência na administração pública: o que mudou depois da lei de responsabilidade fiscal? Um estudo exploratório em seis municípios da região metropolitana de Salvador. Revista de Contabilidade da UFBA, v. 1, n. 1, 2007.

SILVA, A. R.. Metodologia da pesquisa aplicada à contabilidade: orientações de estudos, projetos, relatórios, monografias, dissertações, teses. São Paulo: Ed. Atlas, 2003.

SILVA, L. M. Contabilidade governamental: um enfoque administrativo da nova contabilidade pública. 9 ed. Atlas: São Paulo: 2011.

SLOMSKI, V.; CAMARGO, G. B.; AMARAL FILHO, A. C. C.; SLOMSKI, V. G. A demonstração do resultado econômico e sistemas de custeamento como instrumentos de evidenciação do cumprimento do princípio constitucional da eficiência, produção de governança e accountability no setor público: uma aplicação na Procuradoria-Geral do Município de São Paulo. Revista de Administração Pública, v.44, n.4, p. 933-937, 2010. 